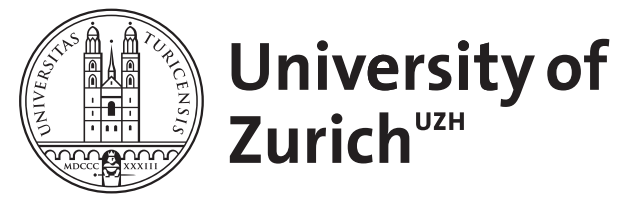

Zurich Open Repository and Archive

University of Zurich

University Library

Strickhofstrasse 39

CH-8057 Zurich

www.zora.uzh.ch

Year: 2007

The economic evaluation of prevention - Let's talk about values and the case of discounting

Schwappach, David L B

DOI: https://doi.org/10.1007/s00038-007-0231-4

Posted at the Zurich Open Repository and Archive, University of Zurich

ZORA URL: https://doi.org/10.5167/uzh-155742

Journal Article

Published Version

Originally published at:

Schwappach, David L B (2007). The economic evaluation of prevention - Let's talk about values and the case of discounting. Sozial- und Präventivmedizin, 52(6):335-336.

DOI: https://doi.org/10.1007/s00038-007-0231-4 


\title{
The economic evaluation of prevention - Let's talk about values and the case of discounting
}

\author{
David L.B. Schwappach \\ PD Dr. David L.B. Schwappach is Head of Research at the Research Institute for Public Health and Addiction (ISGF) Zurich, Switzerland
}

"Does prevention pay off?" is a question frequently directed at health economists, and, as they are economists, they usually respond "it depends". The good news is that health economic evidence on prevention has steadily increased over the past years and a number of interventions have proven favourable cost-effectiveness ratios (Wang et al. 2001; Murray et al. 2003). The bad news is that this growth has been highly selective, and many of the studies lack quality. In a recent systematic review we found that the majority of economic evaluations that assessed interventions for primary prevention of cardiovascular disease are pharmacoeconomic studies of clinical prevention that target dyslipidemia and typically refer to subjects aged 35-64 years old or seniors (Schwappach et al. 2007). Clearly, the rise of economic evaluation studies in the last years can predominantly be explained by an increased interest of the pharmaceutical industry to prove the cost-effectiveness of chemoprevention. Studies that evaluated the economics of broader health promotion interventions, and in particular those addressing the health of children and adolescents are still very rare. This is surprising since advocates of health promotion often emphasize the value of so-called "early prevention". Unfortunately, there is yet only little economic data to support this notion. Many health economic evaluations of prevention are of poor methodological quality and fail to provide even basic information necessary for a meaningful interpretation of results, for example, documentation of study perspective or costing year. However, such weaknesses are not unique to the assessment of preventive care, though some problems seem more pronounced in this area (Neumann et al 2000; Schwappach \& Boularte 2007). For example, longer time periods and rather fragile causal relationships as often observed in preventive care lead to higher levels of uncertainty that need to be modelled appropriately. Clearly, stricter adherence to health economic guidelines is necessary in the evaluation of prevention, care and cure. Leaving these limi- tations aside for the moment, and overcoming the appeal to name and shame specific interventions with more or less favourable results in terms of cost-effectiveness, what can we learn from the economic evaluation of prevention on a more general level? Above all, we see that there are several methodological aspects in the practice of economic evaluation that bias against preventive care. While often regarded as mere "technicalities" many of these practical features reflect, or mask, how societies value the future health against current lives. In particular, the debate about approaches and rates of discounting is often perceived as financial arithmetic by non-economists. Discounting refers to the concept of adjusting future costs and benefits occurring at different points in time to their present 'net' value based on the assumption of a positive rate of time preference. If, as an example, an intervention costs 1000,5000 , and $10.000 €$ in the first, second and third year respectively, the net value today inflated at an annual $5 \%$ discount rate would be $14.832 €$ rather than $16.000 €$. If, however, as in prevention, costs (e.g., 10.000€) occur today while benefits (e.g., 15 life years saved) occur in 20 years, the discounted cost-effectiveness ratio would be $10.000 / 5,65$ (or $1770 €$ per life year), rather than the - undiscounted $-10.000 / 15$ (or $667 €$ per life year). The assumptions underlying discounting procedures are pure value judgments aiming to reflect human time preferences towards immediate benefits and postponement of costs into the future. In line with most guidelines current discounting practice overwhelmingly adopts uniform and constant discount rates for both costs and health benefits, making the cost-effectiveness of prevention appear less favourable than curative approaches (Gravelle \& Smith 2001; Hjelmgren et al. 2001). While there are a number of theoretical arguments to support uniform discounting, e.g., consistency and avoidance of postponement paradoxes (Lazaro 2002; Keeler \& Cretin 1983), there is also empirical evidence that individual preferences (which are, in fact, the main 
argument for discounting) depart from uniform non-variable discount rates for costs and benefits. Findings rather imply a need for a discount rate that declines with time (Cairns \& Van der Pol 1997; Cairns \& Van der Pol 2000). Non-uniform, differential discounting 'devalues' future health benefits much less than uniform discounting does and prevention would thus appear more favourable than it presently seems in health economic evaluations. Compared to a constant rate, a declining discount rate for both costs and benefits would support public health interventions with costs now and outcomes in the distant future, or even next generation, as is the case with many preventive interventions. As Severens and Milne argue, neither theoretical nor empirical arguments are adequate to determine an optimal solution regarding which discounting method rate should be used (Severens \& Milne 2004). Decision makers need to discuss whether the current practice of using uniform discounting at a constant non-zero discount rate, which obviously leads to systematic prioritization of immediate treatment is in concordance with national policies. Similar conclusions regarding systematic effects that work against prevention can be drawn from the question which future costs of related and unrelated illnesses need to be considered. The current practice of excluding future costs seems to bias against preventive interventions, in particular those targeted at younger age groups (van Baal et al. 2007). Finally, there remains a bunch of questions related to the comparative valuation of health effects obtained by preventive versus curative health care. Here, the core question is whether the current practice of estimation of health benefits, namely, that the benefit of preventing a health state equals the inverse of being in that state, is valid and reflects social preferences (Schwappach 2002a). There is some evidence that people place more value on cure when asked to compare directly the benefits of prevention and treatment under resource constraints, but further research is clearly needed (Ubel et al. 1998; Schwappach 2002b; Corso et al. 2002). At the end of the day, after unwrapping technicalities, the main question remains as to how we value the quality and length of future lives against the quality and length of current lives.

David L.B. Schwappach

\section{References}

Cairns J, van der Pol M (2000). Valuing future private and social benefits: The discounted utility model versus hyperbolic discounting models. J Econ Psych 21: 191-205.

Cairns J, Van der Pol M (1997). Constant and decreasing timing aversion for saving lives. Soc Sci Med 45: 1653-1659.

Corso PS, Hammitt JK, Graham JD et al (2002). Assessing preferences for prevention versus treatment using willingness to pay. Med Decis Making 22: S92-101.

Gravelle H, Smith D (2001). Discounting for health effects in cost-benefit and cost-effectiveness analysis. Health Econ 10: 587-599.

Hjelmgren J, Berggren F, Andersson F (2001). Health economic guidelines - similarities, differences and some implications. Value Health 4 : 225-250.

Keeler EB, Cretin S (1983). Discounting of lifesaving and other nonmonetary effects. Management Science 29: 300-306.

Lazaro A (2002). Theoretical arguments for the discounting of health consequences: where do we go from here? Pharmacoeconomics 20: 943-961.
Murray CJ, Lauer JA, Hutubessy RC et al. (2003). Effectiveness and costs of interventions to lower systolic blood pressure and cholesterol: a global and regional analysis on reduction of cardiovascular-disease risk. Lancet 361: 717-725.

Neumann PJ, Stone PW, Chapman RH et al. (2000) The quality of published cost-utility analyses, 1976-1997. Ann Intern Med 132: 964-972.

Schwappach DL (2002a). Resource allocation, social values and the QALY: a review of the debate and empirical evidence. Health Expect 5: 210-222.

Schwappach DL (2002b). The equivalence of numbers: The social value of avoiding health decline: An experimental web-based study. BMC Med Inform Decis Mak 2.

Schwappach DL, Boluarte TA (2007). HEE-GER: A systematic review of German economic evaluations of health care published 1990-2004. BMC Health Serv Res 7: 7.

Schwappach DL, Boluarte TA, Suhrcke M (2007). The economics of primary prevention of cardiovascular disease - a systematic review of economic evaluations. Cost Eff Resour Alloc 5: 5.
Severens JL, Milne RJ (2004). Discounting health outcomes in economic evaluation: the ongoing debate. Value Health 7: 397-401.

Ubel PA, Spranca MD, DeKay ML et al. (1998). Public preferences for prevention versus cure: what if an ounce of prevention is worth only an ounce of cure? Med Decis Making 18: 141-148.

van Baal PH, Feenstra TL, Hoogenveen RT et $a l$. (2007). Unrelated medical care in life years gained and the cost utility of primary prevention: in search of a 'perfect' cost-utility ratio. Health Econ 16: 421-433.

Wang LY, Crossett LS, Lowry R et al. (2001). Cost-effectiveness of a school-based tobacco-use prevention program. Archives of Pediatric and Adolescent Medicine 155: 1043-1050.

Address for correspondence

PD Dr. David Schwappach, MPH Research Institute for Public Health and Addiction

WHO Collaborating Centre for Substance Abuse

Konradstrasse 32

CH-8031 Zuerich Switzerland e-mail: david.schwappach@ isgf.unizh.ch 